\title{
Deformational brachycephaly: the clinical utility of the cranial index
}

\author{
Ranbir Ahluwalia, BS,,2 Jarrett Foster, BS, ${ }^{1,3}$ Madeleine M. Sherburn, BA, ${ }^{1}$ \\ Georgina E. Sellyn, MA, ${ }^{1}$ Katherine A. Kelly, BS, ${ }^{1,4}$ Muhammad Owais Abdul Ghani, MBBS, ${ }^{1}$ \\ Alyssa L. Wiseman, MS, ${ }^{1}$ Chevis N. Shannon, DrPH, MBA, MPH, ${ }^{1,4}$ and \\ Christopher M. Bonfield, MD1,4
}

\begin{abstract}
${ }^{1}$ Surgical Outcomes Center for Kids, Monroe Carell Jr. Children's Hospital at Vanderbilt, Nashville, Tennessee; ${ }^{2}$ Florida State University College of Medicine, Tallahassee, Florida; ${ }^{3}$ University of South Carolina School of Medicine, Columbia, South Carolina; and ${ }^{4}$ Department of Neurological Surgery, Vanderbilt University Medical Center, Nashville, Tennessee
\end{abstract}

\begin{abstract}
OBJECTIVE The incidence of deformational brachycephaly has risen since the "Back to Sleep" movement in 1992 by the American Academy of Pediatrics. Brachycephaly prevalence and understanding the dynamic nature of the pediatric skull have not been explored in relation to the cranial index $(\mathrm{Cl})$. The objective of the study was to determine the prevalence of brachycephaly, via the $\mathrm{Cl}$, with respect to time.
\end{abstract}

METHODS The authors conducted a retrospective review of 1499 patients $\leq 19$ years of age who presented for trauma evaluation with a negative CT scan for trauma (absence of bleed) in 2018. The Cl was calculated using CT at the lateralmost point of the parietal bone (cephalic width), and the distance from the glabella to the opisthocranion (cephalic length). Brachycephaly was defined as a $\mathrm{Cl} \geq 90 \%$.

RESULTS The mean $\mathrm{Cl}$ was 82.6 , with an average patient age of 6.8 years. The prevalence of deformational brachycephaly steadily decreased from $27 \%$ to $4 \%$ from birth to $>2$ years of life. The mean $\mathrm{Cl}$ was statistically different between ages < 12 months, 12-24 months, and > 24 months $(F[2,1496]=124.058, p<0.0005)$. A simple linear regression was calculated to predict the $\mathrm{Cl}$ based on age; the $\mathrm{Cl}$ was found to decrease by 0.038 each month. A significant regression equation was found $(F[1,1497]=296.846, p<0.0005)$, with an $R^{2}$ of 0.140 .

CONCLUSIONS The incidence of deformational brachycephaly is common in infants but decreases as the child progresses through early childhood. Clinicians can expect a significant decrease in mean $\mathrm{Cl}$ at 12 and 24 months. Additionally, these regression models show that clinicians can expect continued improvement throughout childhood.

https://thejns.org/doi/abs/10.3171/2020.2.PEDS19767

KEYWORDS brachycephaly; cranial index; "Back to Sleep"; craniofacial

$\mathrm{P}$ REDOMINANTLY occurring in infants, brachycephaly is defined as symmetric flattening of the occiput typically caused by an external force pushing on the skull. ${ }^{1}$ As a result, compensatory parietal widening occurs, thus creating a disproportionately short and wide head shape. ${ }^{1,2}$ The rise in the prevalence of brachycephaly and other deformational skull conditions can be a consequence of infant sleep positions. ${ }^{3}$ Specifically, the incidence of brachycephaly has increased since the American Academy of Pediatrics (AAP) initiated the "Back to Sleep" movement in 1992, recommending children sleep supine to reduce the risk of sudden infant death syndrome. ${ }^{3-5}$
Since the inception of this campaign, it has been difficult to determine the prevalence of brachycephaly within the population.

The cranial, or cephalic, index (CI) is a metric designed to measure the effectiveness of cranial deformation correction methods in children, such as helmet use for brachycephaly. ${ }^{6}$ The CI is calculated by the following formula: (cephalic width/cephalic length) $\times 100 .{ }^{6}$ Cephalic width is the measurement from the most lateral point on either side of the skull, and cephalic length is the measurement between the most anterior and posterior points of the skull? The CI definition of brachycephaly is not standardized. 


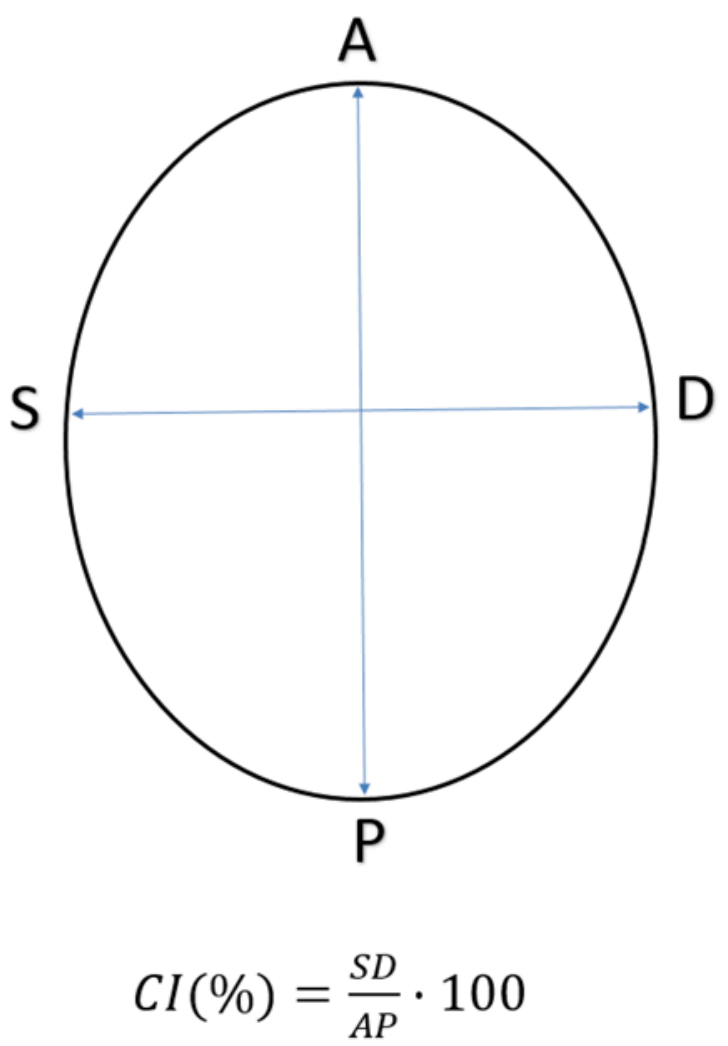

FIG. 1. Schematic representation of $\mathrm{Cl}$ measurement. Figure is available in color online only.

The cutoff CI used to define brachycephaly has been a contested point in the literature, with a range of $81 \%$ to $95 \%$; $^{4-6}$ it is evident that there is no established guideline within the literature base.

Thus far, brachycephaly prevalence and understanding the dynamic nature of the pediatric skull have not been explored in relation to CI. This study measured CI in 1499 children who presented to Monroe Carell Jr. Children's
Hospital at Vanderbilt (MCJCHV), to gain insight into the condition's prevalence and progression. The authors investigated differences in CI with respect to age groups, and specifically within the first 2 years of life. We hypothesized that brachycephaly prevalence decreases with age, and that there is a natural correction of the CI with respect to time. This understanding could provide physicians with greater insight into the natural progression of brachycephaly, and more accurately inform families about resolution of skull asymmetry.

\section{Methods}

A cross-sectional review was conducted of pediatric patients evaluated for head trauma with a negative CT scan at MCJCHV between January 1, 2018, and December 31,2018 . The inclusion of study participants was based on the following criteria: 1) patients were $\leq 19$ years of age at the time of CT; 2) patients were evaluated at MCJCHV; and 3) CT results were negative for posttraumatic focal or diffuse lesions at initial presentation. Exclusion of study participants was based on the following criteria: 1) history of shunted hydrocephalus; 2) radiographic presence of cranial trauma; or 3) history of craniosynostosis or skull surgery. After applying these criteria, 1499 patients were included in our retrospective review.

Patient data were retrospectively reviewed through electronic medical records at MCJCHV. The CI was calculated by measuring the cephalic width as the lateralmost point of the parietal bone, and the cephalic length as the distance from the glabella to the opisthocranion (Figs. 1 and 2). Patients were then grouped into three cohorts to determine changes in CI: $<12$ months, 12-24 months, and $>24$ months. While CI ranges for brachycephaly in the literature are between $81 \%$ and $95 \%$, our study assessed prevalence using a cutoff of $\geq 90 \%$.

Statistical analysis was performed using IBM SPSS Statistics software (version 23.0, IBM Corp.). ANOVA was used to compare CI between the age groups. A scatterplot with linear regression was performed and graphed to evaluate the relationship between age in months and CI.
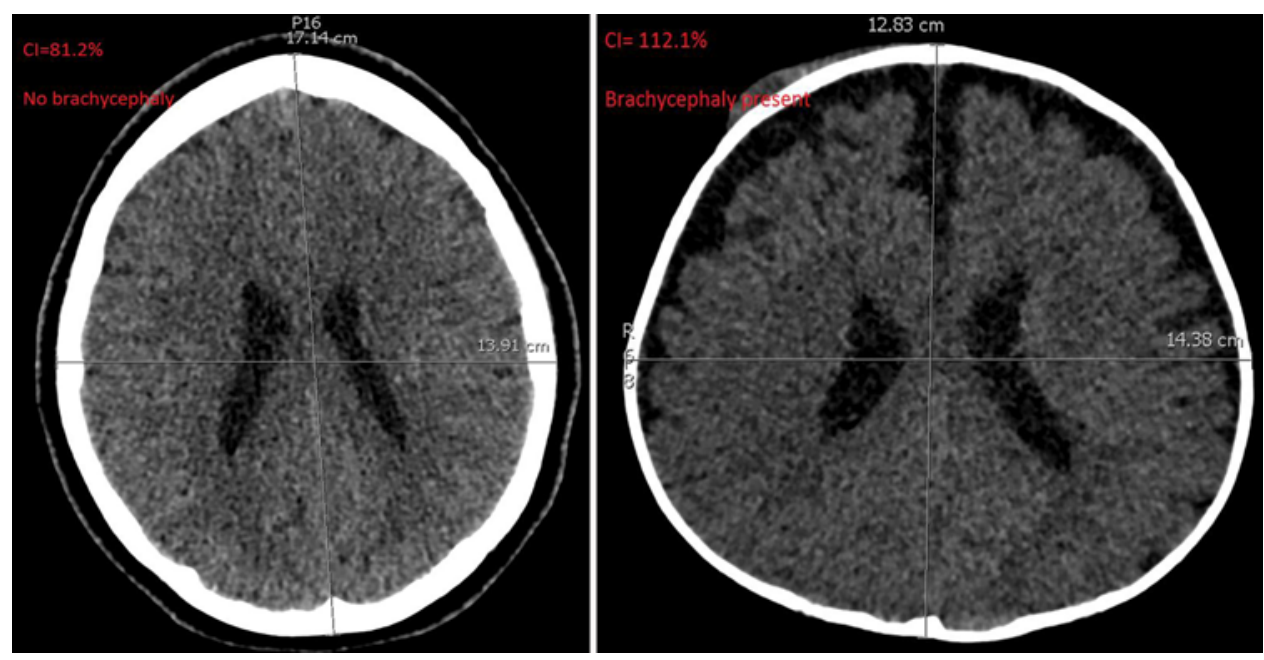

FIG. 2. CT image representation of $\mathrm{Cl}$ measurement. Figure is available in color online only. 
TABLE 1. Patient demographics

\begin{tabular}{lc}
\hline \multicolumn{1}{c}{ Variable } & Value (\%) \\
\hline Sex & \\
Male & $851(56.8)$ \\
Female & $648(43.2)$ \\
\hline Race & \\
White/Caucasian & $1007(67.2)$ \\
Black/African American & $248(16.5)$ \\
Asian/Indian & $24(1.6)$ \\
American Indian or Alaska Native & $6(0.4)$ \\
Other/decline to answer & $214(14.3)$ \\
Ethnicity & $138(9.2)$ \\
Hispanic/Latin American & $1181(78.8)$ \\
Not Hispanic/Latin American & $180(12.0)$ \\
Unknown or decline to answer
\end{tabular}

A Pearson chi-square test was used to determine the proportions of patients who met the definition of brachycephaly. Statistical significance was defined a priori at $\mathrm{p}<0.05$.

\section{Results}

From the total cohort of 1499 patients, the mean age was 6.8 years. Patient demographics are noted in Table 1. The mean CI across the total cohort was 82.6. A simple linear regression was used to examine how well age could predict CI. A scatterplot (Fig. 3) showed that the relationship between age and CI was negative and linear. The correlation between age and CI was statistically significant $(\mathrm{r}=0.165, \mathrm{p}<0.001)$. The equation for predicting CI was found to be $y=85.18-0.04 x(y=C I, x=$ age in months). This relationship shows a decrease in CI by 0.038 each month. A significant regression equation was found
TABLE 2. Mean $\mathrm{Cl}$ by age group

\begin{tabular}{|c|c|c|}
\hline $\begin{array}{l}\text { Age Group } \\
\text { (mos) }\end{array}$ & $\begin{array}{c}\text { Mean } \mathrm{Cl} \\
(95 \% \text { confidence interval) }\end{array}$ & Test Statistic \\
\hline$<12, n=482$ & 85.047 (84.406-85.688) & \multirow{3}{*}{$\begin{array}{c}F(2,1496)=124.058, \\
p<0.0005\end{array}$} \\
\hline $12-24, n=139$ & $84.211(83.158-85.263)$ & \\
\hline$>24, n=878$ & $80.410(79.985-80.835)$ & \\
\hline
\end{tabular}

$(\mathrm{F}[1,1497]=296.846, \mathrm{p}<0.0005)$, with an $\mathrm{R}^{2}$ of 0.140 , demonstrating a negative relationship between $\mathrm{CI}$ and age. Post hoc analysis revealed significant differences between age groups, with the younger cohorts having higher mean CI values $(\mathrm{F}[2,1496]=124.058, \mathrm{p}<0.0005$; Table 2 , Fig. 4). The prevalence of brachycephaly (Fig. 5), as defined radiographically by a $\mathrm{CI} \geq 90 \%$, showed a consistent, significant decline across patient age groups: $<12$ months (28.0\%), 12-24 months (12.9\%), and > 24 months (4.2\%; $\left.\mathrm{X}^{4}=158.96, \mathrm{r}=-0.322, \mathrm{p}<0.001\right)$.

\section{Discussion}

This study investigated the incidence of deformational brachycephaly in children, and how it changes in relation to different ages. We hypothesized that brachycephaly prevalence decreases with age, and that there is a natural correction of the CI with respect to time. Cultural norms create a notion of what is considered "symmetrical," and historically a dolichocephalic head shape was considered the norm. ${ }^{8}$ However, since the AAP released the Back to Sleep campaign, the incidence of plagiocephaly and brachycephaly has been steadily increasing. ${ }^{4}$ Thus, the accepted standard of skull shape has a dynamic definition as a result of sleeping position. The natural history of both

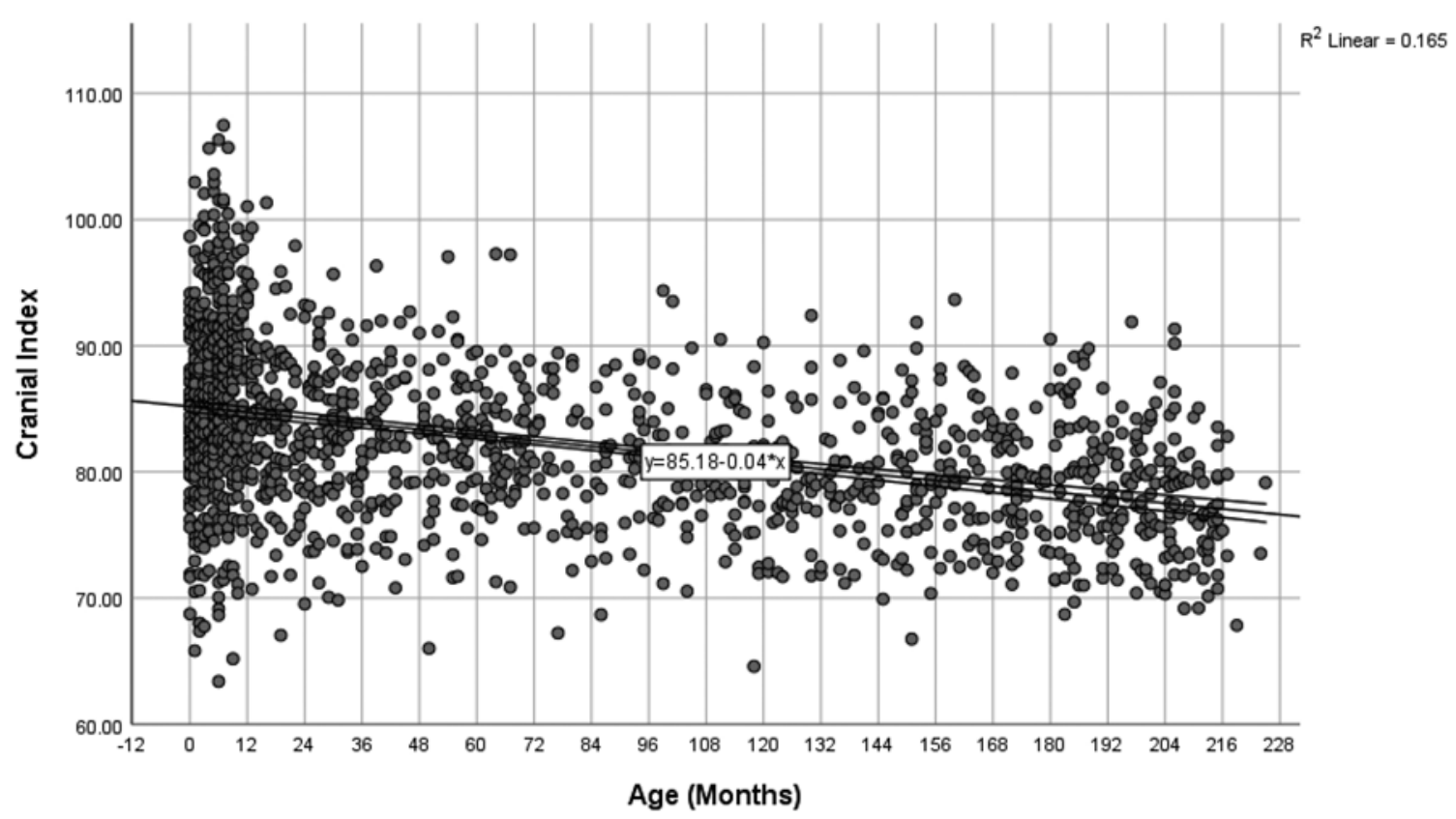

FIG. 3. Scatterplot of $\mathrm{Cl}$ by age and $\mathrm{Cl}$ severity. This graph demonstrates the negative linear relationship between age and $\mathrm{Cl}$. 


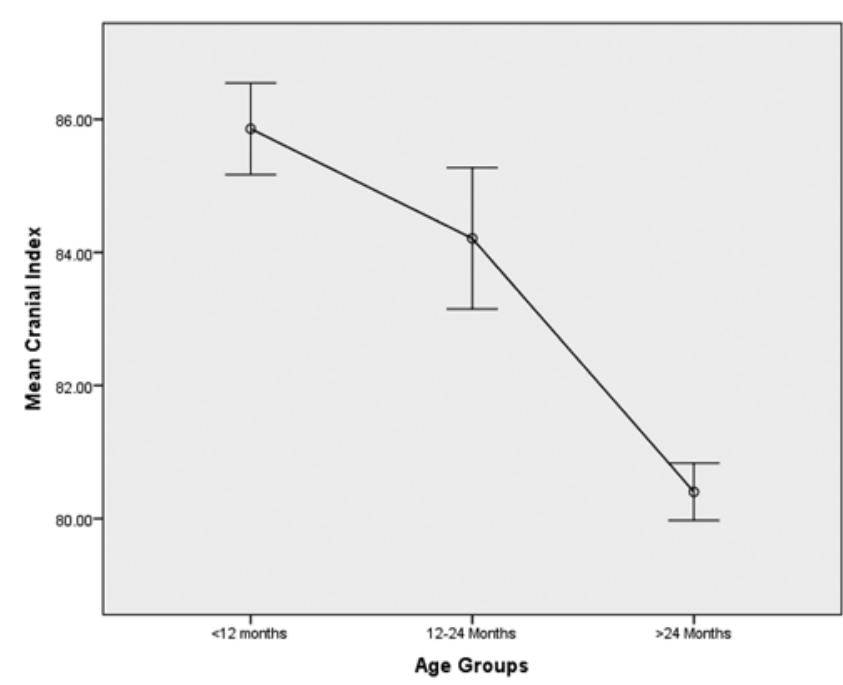

FIG. 4. Graphic representation of mean $\mathrm{Cl}$ by age groups.

deformational brachycephaly and plagiocephaly diminishes in adolescence due to brain growth and decreased force on the skull. ${ }^{4}$ Given that these conditions are benign in nature, the major concern is cosmetic acceptance. Ultimately, however, Feijen et al. demonstrated that head asymmetry is not a determinant in the self-evaluation of appearance during adolescence. ${ }^{4}$

There is no study to date that has evaluated the natural history of CI with respect to brachycephaly. The evolution, prevalence, and resolution of plagiocephaly have received more attention in the literature..$^{9-12}$ The utility of CI has primarily been to determine the recovery progression of brachycephaly after helmet therapy, but the first-line treatment is repositioning therapy. ${ }^{5}$ Perhaps the modern notion of skull asymmetry represents a spectrum rather than individual domains. Plagiocephaly and brachycephaly may exist on a continuum. ${ }^{13}$ As such, the only study evaluating the natural resolution of plagiocephaly/brachycephaly was performed by Hutchison et al., ${ }^{10}$ who observed a decrease in diagnosis rate from $16 \%$ to $3.3 \%$ in the first 2 years of life.

Our study has important clinical considerations. First, parents and clinicians should reasonably expect some degree of skull deformity in response to laying children supine. Second, the negative linear association between age and CI suggests that this form of deformity improves with age. Our study is the first to date showing that the degree of change is a decrease of 0.038 in the CI per month over the first 2 years of life. Our analysis demonstrated a statistically significant decrease in the mean CI at 12 and 24 months. From an overall prevalence standpoint, the rapid drop from $28 \%$ to $4.2 \%$ in the first 2 years of life also demonstrates an important trend. This knowledge should help curb any excess anxiety about skull asymmetry and also provide insight into what can be expected for the patient.

Furthermore, the mean $\mathrm{CI}$ in patients greater than 2 years of age was 80.4. As the trend in the overall pediatric population is for children to sleep on their backs as infants, the normative values of the CI might need to be adjusted as well. This is outside of the scope of this

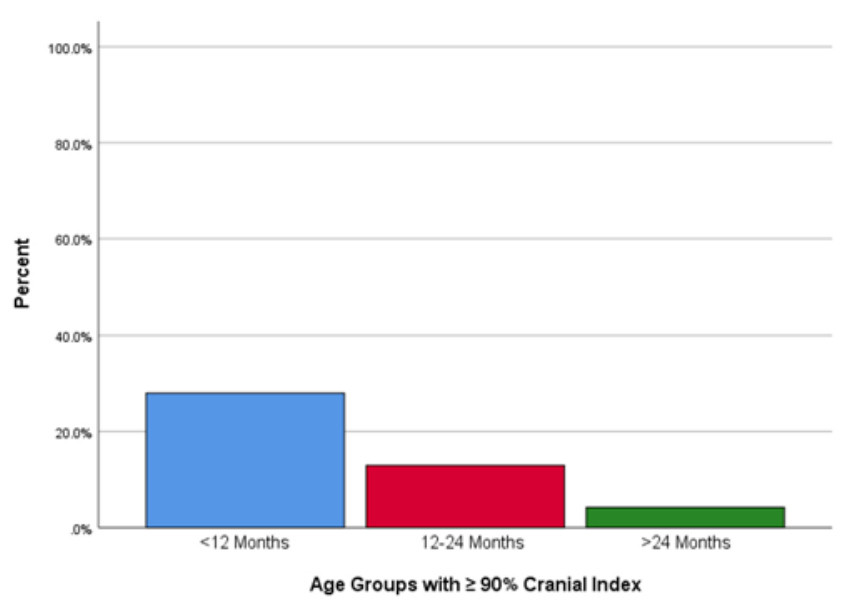

FIG. 5. Percentage of patients with $\mathrm{Cl} \geq 90 \%$ across age groups. Figure is available in color online only.

investigation, but could be investigated with larger populations.

There are a few notable limitations to this study. First, the population is predominantly male and Caucasian/white, which limits the generalizability of the results to other races. Second, this study does not take into account the natural history of posterior positional plagiocephaly. Third, our study does not take into consideration patients who may have been treated via helmet therapy. Because this study focuses on an initial trauma evaluation, there is no follow-up and treatment records are unknown in the outpatient setting. Additionally, by virtue of using CT scans to determine brachycephaly diagnosis, there is no clinical correlation provided. Due to potential differences in skull shape, head positioning, and gantry angle, measurements may be subject to subtle variation.

\section{Conclusions}

The incidence of deformational brachycephaly is common in infants but decreases as the child progresses through early childhood. Clinicians can expect a significant decrease in mean CI at 12 and 24 months. Additionally, our regression models show that clinicians can expect continued improvement throughout childhood.

\section{References}

1. Rogers GF. Deformational plagiocephaly, brachycephaly, and scaphocephaly. Part I: terminology, diagnosis, and etiopathogenesis. J Craniofac Surg. 2011;22(1):9-16.

2. Kelly KM, Joganic EF, Beals SP, et al. Helmet treatment of infants with deformational brachycephaly. Glob Pediatr Health. 2018;5:X18805618.

3. Turk AE, McCarthy JG, Thorne CH, Wisoff JH. The "back to sleep campaign" and deformational plagiocephaly: is there cause for concern? J Craniofac Surg. 1996;7(1):12-18.

4. Feijen M, Franssen B, Vincken N, van der Hulst RR. Prevalence and consequences of positional plagiocephaly and brachycephaly. J Craniofac Surg. 2015;26(8):e770-e773.

5. Graham JM Jr, Kreutzman J, Earl D, et al. Deformational brachycephaly in supine-sleeping infants. J Pediatr. 2005;146(2):253-257. 
6. Likus W, Bajor G, Gruszczyńska K, et al. Cephalic index in the first three years of life: study of children with normal brain development based on computed tomography. ScientificWorldJournal. 2014;2014:502836.

7. Waitzman AA, Posnick JC, Armstrong DC, Pron GE. Craniofacial skeletal measurements based on computed tomography: Part II. Normal values and growth trends. Cleft Palate Craniofac J. 1992;29(2):118-128.

8. Hummel P, Fortado D. Impacting infant head shapes. $A d v$ Neonatal Care. 2005;5(6):329-340.

9. Bialocerkowski AE, Vladusic SL, Wei Ng C. Prevalence, risk factors, and natural history of positional plagiocephaly: a systematic review. Dev Med Child Neurol. 2008;50(8):577586.

10. Hutchison BL, Thompson JM, Mitchell EA. Determinants of nonsynostotic plagiocephaly: a case-control study. Pediatrics. 2003;112(4):e316.

11. Lipira AB, Gordon S, Darvann TA, et al. Helmet versus active repositioning for plagiocephaly: a three-dimensional analysis. Pediatrics. 2010;126(4):e936-e945.

12. McKinney CM, Cunningham ML, Holt VL, et al. Characteristics of 2733 cases diagnosed with deformational plagiocephaly and changes in risk factors over time. Cleft Palate Craniofac J. 2008;45(2):208-216.

13. Meyer-Marcotty P, Böhm H, Linz C, et al. Spectrum of positional deformities - is there a real difference between plagiocephaly and brachycephaly? J Craniomaxillofac Surg. 2014;42(6):1010-1016

\section{Disclosures}

The authors report no conflict of interest concerning the materials or methods used in this study or the findings specified in this paper.

\section{Author Contributions}

Conception and design: Ahluwalia, Shannon, Bonfield. Acquisition of data: Ahluwalia, Foster, Sherburn, Sellyn, Kelly. Analysis and interpretation of data: Ahluwalia, Foster, Sherburn, Sellyn, Ghani. Drafting the article: Ahluwalia, Foster, Sherburn, Sellyn. Critically revising the article: Ahluwalia, Foster, Sellyn, Shannon. Reviewed submitted version of manuscript: Ahluwalia, Foster. Approved the final version of the manuscript on behalf of all authors: Ahluwalia. Statistical analysis: Ahluwalia, Foster, Ghani. Administrative/technical/material support: Ahluwalia, Wiseman, Shannon, Bonfield. Study supervision: Ahluwalia, Wiseman, Shannon, Bonfield.

\section{Correspondence}

Ranbir Ahluwalia: Florida State University College of Medicine, Tallahassee, FL.ra16@med.fsu.edu. 